\title{
Editorial: state intervention in family life
}

\author{
Sadie Parr* \\ CRESR, Sheffield Hallam University
}

\begin{abstract}
During David Cameron's period of office as Prime Minister (2010-2016) leading the Coalition and the subsequent Conservative governments, there were certain parallels with the former New Labour administrations in which 'the family' took centre stage within social policy. A strong continuity over the last two decades has been the targeting of 'problem' families as both the cause of and the site of solutions to a range of social ills, including crime and anti-social behaviour, educational attainment, poor mental and emotional health and poverty. Following the riots in 2011, in which the blame was placed with 'troublesome' families and deficient parenting, the coalition government's political narrative linked the need to fix the 'broken society' with a requirement to fix the 'broken family'. This brought with it a strengthening of state intervention in the domestic sphere legitimating and giving impetus to the highly contentious Troubled Families Programme which aimed to 'turn around' 120,000 'troubled families'. In 2015, with a wider set of referral criteria, the programme was expanded to include a further 400,000 families.
\end{abstract}

As we near the end of 2016, we are witnessing interesting times for family policy and the future is somewhat uncertain. In July 2016, we saw the appointment of a new Prime Minister, Theresa May, and thus far her public announcements have said little about the future direction of this policy agenda. Family policy has however been thrust into the spotlight on account of the recent publication of the highly critical official evaluation of Troubled Families Programme and the subsequent Public Accounts Committee (PAC) inquiry into the policy. As this particular initiative perhaps reaches a conclusion, it has engendered vibrant debate among academic and social commentators alike on the Troubled Families Programme specifically and on state interventions in parenting and family life more broadly within a wider context defined by economic austerity. This issue of People Place and Policy provides a relevant and timely intervention in these debates, offering thought-provoking reflection and analysis on the current political context.

Turning to the papers in this issue, Stephen Crossley's article examines the nature of state intervention. In part, through the concept of 'troubled families', the author considers how the neoliberal state is being remade, characterised by new and increasing forms of state activity in the lives of marginalised families. Drawing on Michael Lipsky's concept of street-level bureaucrats, the article draws attention to the spaces in which encounters with the state take place. In so doing, the paper highlights how the site of government interventions which target 'the family' have shifted from public spaces into private and domestic spaces. As a consequence, events that take place in other spaces, which also affect the lives of disadvantaged families, are disregarded. 
The second paper moves analytical attention from the rhetorical to consider the 'street-level' practice of the Troubled Families Programme. Sue Bond-Taylor's article reports on interview data collected as part of an evaluation of a 'troubled' family intervention service to highlight the contextual and relational dimensions of the problems which families face. Drawing on a care ethicist's conceptualisation of relational autonomy, the author explores the complexity of the constraints on multiply disadvantaged families who are struggling to meet normative domestic standards, highlighting the limits of responsibility. The article suggests that, underpinned by an adequately theorised understanding of the problems families face, family interventions might be repositioned as an opportunity to support families and, in particular, mothers, to overcome oppressive conditions which constrain their capacity to act.

Many of the challenges associated with implementing the Government's current 'troubled families' programme have their precedents in the past. The third paper by Michael Lambert also addresses debates about the 'problem family' but through a historical lens. The author provides a critical examination of Adam Perkins' controversial book The Welfare Trait in which the author makes claims for the existence of a 'welfare-induced', 'employment-resistant' type of personality, transmitted across generations of problem families. The article examines Perkins' arguments by reconstructing research undertaken by psychiatrist William Tonge and others in Sheffield during the 1960 s and 1970s, which Perkins relies heavily upon. In so doing, the article demonstrates the weaknesses of essentialising narratives of difference presented under a veneer of scientific credibility.

The final article by David Marjoribanks and Keith Davies engages directly with the present context of political uncertainty, by taking stock of recent family policy trends. The authors raise concerns regarding the effects of previous family policy developments with particular reference to parenting and relationship support. Attention is focused on the 'Life Chances Strategy' which was due to be launched on 24th June 2016, immediately after the EU Referendum, but which has since been put on hold following David Cameron's resignation. The article analyses and explores that part of the strategy concerned with the family and early years. Looking forward, the authors argue that 'whole-family' approaches characteristic of the Troubled Families Programme, alongside the 'life course' narrative of the Life Chances Strategy, offer a framework for what an integrated and coherent approach to family, relationships and parenting policy might look like.

* Correspondence address: Dr Sadie Parr, CRESR, Unit 10, Science Park, Howard Street, Sheffield, S1 1WB. Email: s.parr@shu.ac.uk 